\title{
APLICAÇÃO DE IMPRESSÕES 3D COMO RECURSO DIDÁTICO PARA O ENSINO DO COMPONENTE CURRICULAR ESTRUTURAS DE AÇO NA UFERSA - CMPF
}

\author{
APPLICATION OF 3D PRINTINGS AS A DIDACTIC RESOURCE FOR TEACHING \\ STRUCTURAL STEEL CURRICULAR COMPONENT AT UFERSA - CMPF \\ José Henrique Maciel de Queiroz ${ }^{1}$, Matheus Fernandes de Araújo Silva², \\ Hortência Pessoa Rego Gomes ${ }^{3}$
}

DOI: $10.37702 / R E E 2236-0158 . v 39 p 70-78-.2020$

\begin{abstract}
RESUMO
Na Universidade Federal Rural do Semi-Árido, Centro Multidisciplinar Pau dos Ferros, uma das dificuldades apresentadas pelos discentes do componente curricular Estruturas de Aço no semestre 2018.1 foi a dificuldade de compreender representações bidimensionais de estruturas. Visando a fornecer alternativas para contornar a problemática, propõe-se neste trabalho a adoção da tecnologia de impressão 3D. Com uma impressora 3D foram construídas, então, peças representativas de elementos comumente presentes no projeto de estruturas metálicas, explanadas pelo docente em suas aulas. Essas peças foram utilizadas para a complementação da didática do docente, expondo-se conceitos de forma mais interativa e realística. Qualitativamente, foi avaliada a percepção dos integrantes da turma em relação a esse recurso didático, mostrando-se a sua importância e impacto sobre o aprendizado dos discentes. Todos os discentes entrevistados durante a pesquisa se mostraram satisfeitos com a implementação da tecnologia em aula, ressaltando que ela realmente os auxiliou na assimilação dos conceitos discutidos no âmbito do componente Estruturas de Aço. Percebeu-se ao longo do trabalho que esse tipo de solução aprovada pelos alunos é também uma forma de complementar sua formação.
\end{abstract}

Palavras-chave: impressão 3D; estruturas de aço; ensino; didática.

\begin{abstract}
At the Universidade Federal Rural do Semi-Árido, Centro Multidisciplinar Pau dos Ferros, one of the difficulties presented by the students of the curricular component Structures of Steel in the semester 2018.1 is to understand two-dimensional representations of structures. In order to provide alternatives to overcome this problem, it is proposed in this work the adoption of 3D printing technology. With a 3D printer were constructed, pieces representative of elements commonly present in the design of metal structures, explained by the teacher in his class. These pieces were used to complement the didactics of the teacher, exposing concepts in a more interactive and realistic way. Qualitatively, it was evaluated the perception of the members of the class in relation to this didactic resource, showing its importance and impact on students' learning. All the students interviewed during the research were satisfied with the implementation of the technology in class, emphasizing that it really helped them in the assimilation of the concepts discussed in the scope of the Structures of Steel component. It was realized throughout the work that this type of solution approved by students is also a way of complementing their training.
\end{abstract}

Keywords: 3D printing; steel structures; teaching; didactics. 


\section{INTRODUÇÃO}

As representações das estruturas projetadas pelos engenheiros civis geralmente são feitas em duas dimensões (2D). Ao se analisar os problemas relacionados ao dimensionamento de estruturas de aço, especialmente, o entendimento dessas representações deve ser completo: abrangendo as formas estudadas, as disposições construtivas, as conexões etc.

No meio universitário, os estudantes precisam desenvolver e exercitar a sua capacidade de interpretar os problemas na forma $2 \mathrm{D}$, pois o comportamento estrutural depende de interações tridimensionais (3D) que devem ser detectadas e consideradas a partir dos desenhos em 2D. Assim, os alunos podem sentir algumas dificuldades nessa fase de aprendizado, pois, algumas vezes, é na universidade que se dá o primeiro contato do aluno com as estruturas metálicas.

Entretanto, esse tipo de dificuldade pode vir a comprometer o ritmo da aula, levando a repetições de explicação pelo professor e consequentemente gerando menor rendimento do componente curricular. Sendo assim, esta pesquisa buscou testar - como alternativa para amenizar esse problema - o uso de impressões 3D como recurso didático durante o ensino dos conteúdos do componente curricular Estruturas de Aço na Universidade Federal Rural do Semi-Árido (UFERSA), Centro Multidisciplinar Pau dos Ferros (CMPF).

\section{EDUCAÇÃO E TECNOLOGIA}

De acordo com Vaillant e Marcelo (2012), em decorrência do desenvolvimento da humanidade em geral, existe uma demanda de atualização das formas de ensino. Segundo os autores, as mudanças sociais que envolvem a relação interpessoal entre professor e aluno bem como a evolução tecnológica devem estar integradas às salas de aulas modernas, trazendo, dessa forma, novos desafios e oportunidades ao professor. Conjuntamente a isso, surge uma necessidade de se modificar as metodologias de ensino e de se discutir o papel do professor na formação profissional.

Nesse sentido, é possível afirmar que as tecnologias emergentes não só podem ser utilizadas como instrumentos de ensino, mas também que devem constituir um ponto a ser considerado pelo professor, podendo trazer melhoria e adequação do ensino à realidade atual. Além disso, Feldkercher (2015) expõe a defesa atual de uma oferta de experiências ricas e sedutoras aos jovens em aprendizado, para que, por meio da tecnologia, possa ser despertado o interesse pela pesquisa e pelo estudo.

Ademais, conforme Machado e Lima (2017), as tecnologias fazem parte do dia a dia dos alunos, de tal modo que eles esperam que o professor faça uso delas em sala de aula e que ele, dessa vez na posição de mediador entre o conhecimento, a tecnologia e o aluno, desencadeie habilidades e competências antes não exploradas, em si mesmo e no aluno. Assim, para o docente, é importante que conheça as tecnologias para desenvolver um planejamento de aula adequado ao seu conteúdo e que procure interagir com os alunos no processo de ensino aprendizagem. (MORAN, 2000).

Esse planejamento envolve estratégias metodológicas de ensino e utilização dos recursos didáticos. Os recursos didáticos são recursos tanto humanos quanto materiais, utilizados pelo professor em sua atividade profissional, com o objetivo de auxiliar e facilitar a aprendizagem do estudante.

Segundo o pensamento de Karling (1991), os recursos didáticos são importantes para que o educando receba informações a partir dos seus sentidos e estas se transformem em percepções - seja por meio de imagens, fatos, situações, experiências, demonstrações etc. Os recursos didáticos possuem também um papel incentivador: ao instigar o aluno sobre determinada situação, pode fazê-lo prestar mais atenção na aula, levantar questionamentos, hipóteses e desenvolver pesquisa. 


\section{A IMPRESSÃO 3D}

De acordo com Aguiar (2016), a impressão 3D é uma tecnologia caracterizada pelo processo em que se materializa um objeto tridimensional por meio da adição e sobreposição de camadas de um certo material até que se obtenha a forma final do sólido. $\mathrm{O}$ autor acrescenta que essa técnica também é conhecida como manufatura aditiva, por ir acrescentando gradualmente a matéria-prima, diferentemente de outras técnicas.
Pela versatilidade que as máquinas de impressão 3D apresentam, estas conseguem atender a muitas demandas de uma forma prática e com um custo relativamente baixo. $\mathrm{O}$ uso delas pode ser útil desde ao entretenimento até à prototipagem, à medicina à arquitetura e à engenharia. Este trabalho se propõe a abordar sua utilidade à engenharia, mais especificamente à área do conhecimento da Engenharia de Estruturas.

A obtenção dos objetos por intermédio da impressão 3D é realizada através de várias etapas, as quais podem der observadas no Fluxograma 01.

Fluxograma 01 - Processo de obtenção de objetos impressos em 3D

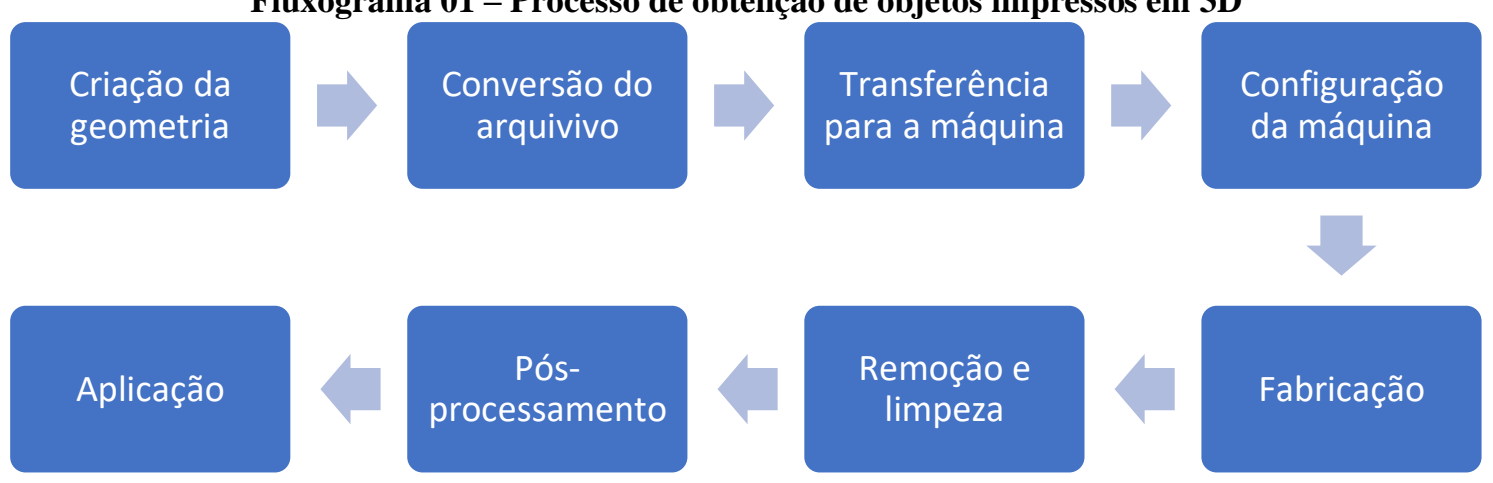

Fonte: Adaptado de Gibson et al., 2010 apud Martins, 2017.

Para este trabalho, selecionou-se, juntamente com o docente do componente curricular Estruturas de Aço, seis tipos de conexões comumente utilizadas nos projetos com esse tipo de estrutura, que foram submetidas ao completo processo indicado no Fluxograma 01, resultando nas peças mostradas no Quadro 01. As peças foram utilizadas em sala de aula de acordo com os conceitos que seriam capazes de demonstrar.

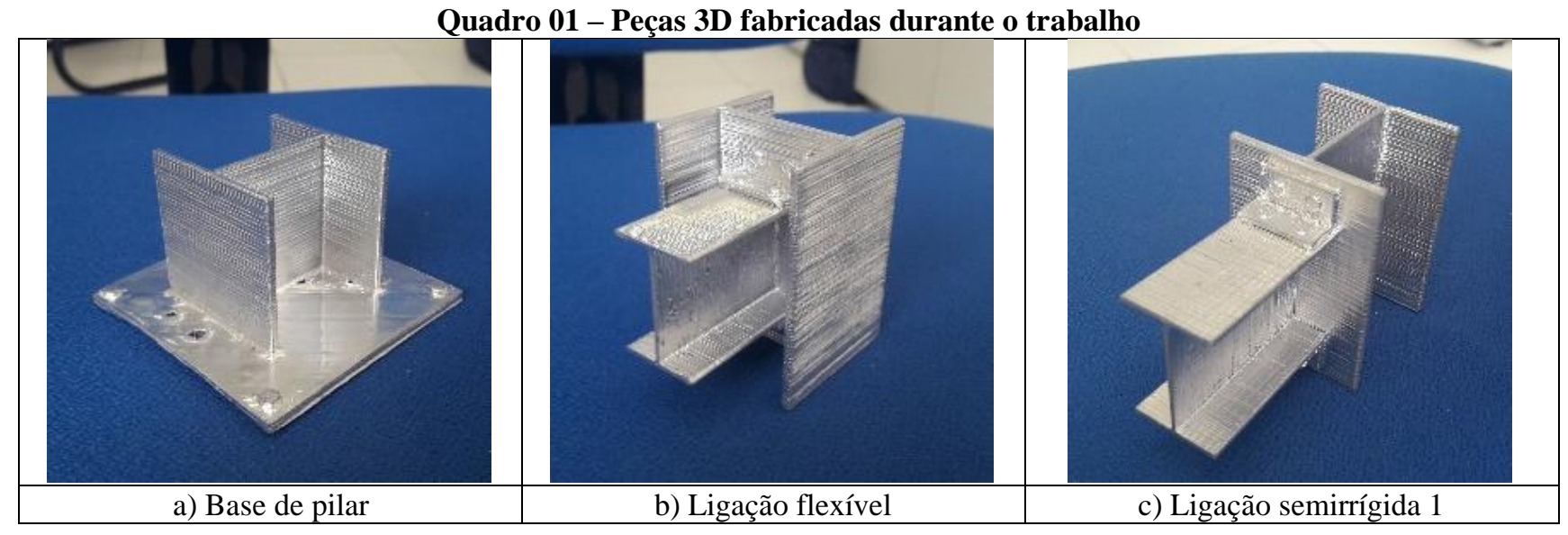




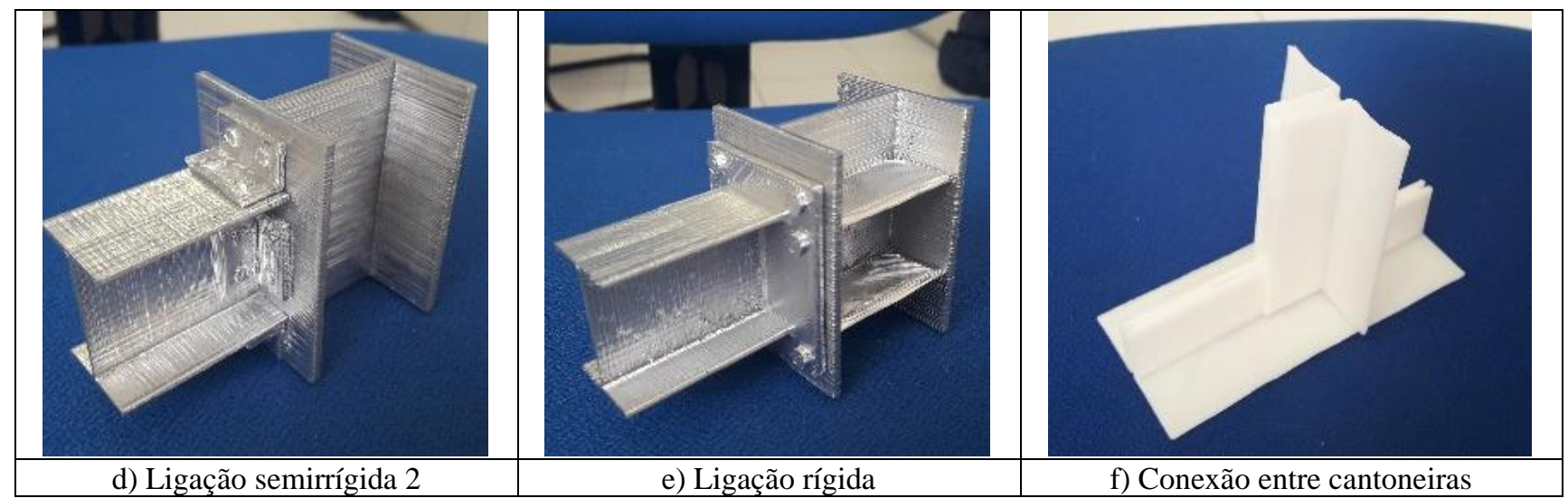

Fonte: elaborado pelos autores, 2018

\section{PROCEDIMENTOS METODOLÓGICOS}

A metodologia adotada foi do tipo experimental, ou seja, utilizou-se de um recurso didático confeccionado no decorrer da pesquisa e que foi experimentado durante sua utilização em sala de aula. Gil (2008) informa que a essência do método experimental está em submeter os objetos de estudo à influência de determinadas variáveis, em condições controladas e conhecidas pelo pesquisador, para observar os resultados provocados pela variável no objeto.

Quanto à forma de abordagem do problema, tem-se uma pesquisa de caráter qualitativo, que busca analisar e interpretar os dados em seu caráter psicossocial.

O campo de estudo da pesquisa foi o Centro Multidisciplinar Pau dos Ferros da Universidade Federal Rural do Semi-Árido. O município de Pau dos Ferros situa-se no interior do estado do Rio Grande do Norte, no Alto Oeste Potiguar, a $398 \mathrm{~km}$ da sua capital, Natal.

Para alcançar os objetivos propostos neste trabalho, utilizou-se, durante as aulas do componente curricular, peças fabricadas via impressão 3D referentes a detalhamentos de estruturas metálicas, no intuito de auxiliar os alunos na compreensão de exemplos e explicações de situações de projeto. Em seguida, com base na aplicação de entrevistas abertas semiestruturadas - ao docente e a uma amostra de discentes da turma matriculada em Estruturas de Aço no semestre 2018.1 da
UFERSA -, obteve-se as informações necessárias para posterior análise dos resultados verificados.

Ressalta-se ainda que a amostra de discentes consultados durante as entrevistas foi obtida aleatoriamente, por sorteio, adotando-se como critério de parada a saturação teórica das informações fornecidas pelos estudantes entrevistados. Dos 44 alunos matriculados, seis deles foram entrevistados.

\section{IMPRESSÕES 3D E SUAS INFLUÊNCIAS}

De acordo com Tulio (2013), a adequada utilização dos recursos didáticos em aula depende de um bom planejamento, da definição dos objetivos a serem alcançados e da sequência didática elaborada para que o conteúdo proposto seja trabalhado. Nesse sentindo, avaliando-se o caso da aplicação das impressões 3D que observamos, foi possível perceber que tais critérios foram atendidos.

Logo nas etapas iniciais deste trabalho, as impressões 3D foram uma alternativa bem recebida pelo docente de Estruturas de Aço para complementação de sua didática, pois ele já vinha notando, há algum tempo, o entrave de alguns discentes na resolução de certos exercícios, com dúvidas atreladas não ao processo de dimensionamento, mas sim à compreensão da estrutura.

Essa característica foi bastante importante para o prosseguimento e para a correta implementação do recurso didático no processo ensino-aprendizagem dos discentes 
do semestre letivo 2018.1 da UFERSA-CMPF. Graças a isso pôde-se realizar a impressão das peças consideradas mais relevantes para $\mathrm{o}$ entendimento dos conceitos do componente curricular e planejar de forma mais assertiva em quais aulas, em quais momentos e juntamente com que outros instrumentos as impressões iriam atuar.

Conforme a opinião dos participantes da entrevista, quando questionados sobre a forma como o recurso foi utilizado durante as aulas, todos julgaram que foi de maneira adequada ao aprendizado, complementando as teorias abordadas e aproximando o aluno da situação real. Podemos perceber essa aprovação na fala do participante 3, que relatou: "Foi no momento ideal, ele pegou as estruturas já juntamente com o conteúdo, associando".

Além disso, a implementação desse recurso não descartou o uso conjunto de outros recursos anteriormente existentes: o professor fazia a exposição do conteúdo no quadro branco, em seguida utilizava o modelo 3D impresso para mostrar a forma como uma ligação, por exemplo, era executada e, ainda, complementava a visão do aluno com registros fotográficos de situações práticas similares. Os discentes exploravam, então, três sentidos - a audição (explanação da teoria); a visão (registros fotográficos e peças); e o tato (toque nas peças). As peças foram ainda utilizadas durante algumas aulas de monitoria do componente curricular, buscando-se facilitar a solução de dúvidas dos estudantes surgidas posteriormente à aula comum.

Segundo o pensamento de Ferreira (1975 apud Barbosa, 2001), os sentidos são responsáveis pela ligação entre o homem e o mundo exterior. Assim, para os fins de efetivar a aprendizagem, é interessante criar um ambiente que permita estimular o maior número de sentidos possível. Estudando os cinco mais importantes sentidos do homem, cientistas concluíram que a visão é o sentido que apresenta maior possibilidade de aprendizagem, seguido da audição, olfato, tato e paladar, respectivamente.

Com isso, o docente nota uma evolução no aprendizado dos alunos que conseguiram ter maior contato com os elementos 3D. Ele afirma que os discentes que puderam ver as peças na monitoria, além de na sala de aulas, superaram as dúvidas básicas que existiam antes, como exemplo perguntas sobre como era feita a ligação de uma viga em um pilar. Após o uso do recurso, o professor afirma que responde a perguntas mais elaboradas do que as anteriores.

$\mathrm{Na}$ opinião dos estudantes entrevistados, as peças realmente os auxiliaram na assimilação de conteúdos e na visualização da estrutura e suas interações; assim, todos eles acharam pertinente o emprego de tal recurso didático no componente curricular. Evidenciamos a seguir a fala do participante 04 e do participante 02 que ratificam a afirmação:

"Com certeza me auxiliaram, porque a partir da impressão $3 D$ você tem uma noção real de como aquela estrutura é. Apesar de ser em dimensões reduzidas, você visualiza qual é o perfil que está sendo utilizado e diversos outros entendimentos." (Participante 04).

"Com certeza, principalmente quando ele levou e estava mostrando os tipos de ligações que tinha nas peças, que eu não conseguia visualizar, aí quando ele mostrava que a viga estava parafusada na alma e na mesa, com a peça você conseguia ver bem direitinho, mas sem elas, teve uma vez até que eu fiquei perguntando: não estou entendendo, não estou entendendo..." (Participante 02).

No Quadro 2 compararmos as representações $3 \mathrm{D}$ obtidas com a impressão e as representações $2 \mathrm{D}$ clássicas: 
Quadro 02 - Ligação flexível, comparação entre representação 3D e 2D

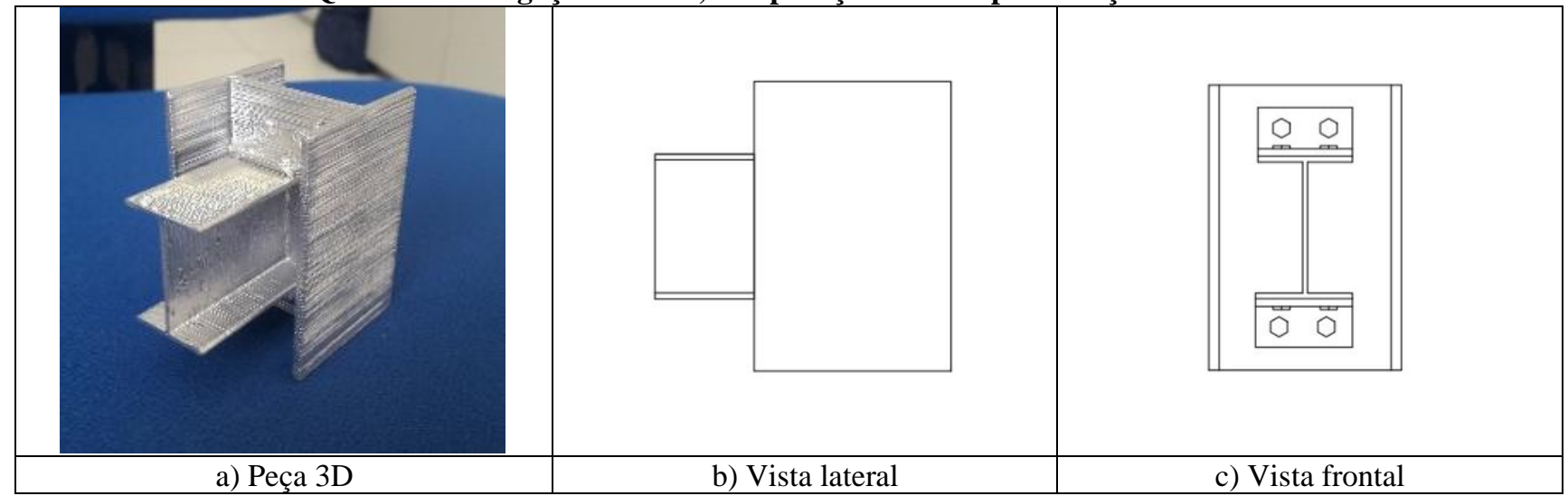

Fonte: elaborado pelos autores, 2018.

Nota-se que para o entendimento de uma conexão completa da estrutura é necessária sua representação $2 \mathrm{D}$ em dois planos diferentes, pois sem isso algumas informações podem ficar ocultas no desenho. Em algumas situações de detalhamento, cortes adicionais devem ser feitos para permitir o entendimento do problema. Em segundo lugar, destacamos a possibilidade de o discente, ao adquirir o contato com a peça tridimensional, girá-la da forma que preferir, visualizando a estrutura da perspectiva que desejar, analisando cada detalhe rapidamente.

Conforme explica Guarnier (2009), é comum aos profissionais da área de estruturas metálicas a ideia de se trabalhar com problemas tridimensionais complexos, pois, dentro de uma estrutura de aço, as ligações sempre incluem elementos que se interceptam, originados de diferentes direções. Assim, as tarefas de solução para tais geometrias dos detalhes da ligação e produção dos desenhos de fabricação são sempre problema a ser solucionado.

Ainda segundo a autora, o avanço da modelagem 2D para 3D de estruturas metálicas provou ser uma das soluções mais viáveis para vencer tais dificuldades. $\mathrm{O}$ poder da modelagem 3D é notório, já que o modelo é, nessa perspectiva, uma completa descrição de todas as peças de aço, parafusos, soldas etc., que constituem o todo ou parte da estrutura de aço que será modelada. Além disso, a estrutura representada é real, em escala, dentro do computador.
Nesse contexto, em relação ao uso do recurso didático, o principal ponto positivo indicado durante as entrevistas foi a capacidade das peças proporcionarem uma visão mais realística das estruturas metálicas, assim aproximando o discente daquela realidade. Ademais, foi mencionado que elas auxiliaram na identificação dos perfis metálicos da estrutura, na compreensão de conceitos de torção, flambagens, momentos, formas de ruptura da estrutura, execução de soldas e parafusamentos. As dimensões, formas, a estrutura e seu funcionamento também ficaram mais claras a partir da implementação do recurso didático.

Durante o uso do recurso didático, alguns fatores, como a disposição do aluno para o estudo do componente curricular, também foram indiretamente afetados. Os estudantes afirmam que a partir do momento em que se entende mais facilmente o conteúdo, o aprendizado, em geral, flui melhor, causando assim maior disposição para a resolução de exercícios além de um maior envolvimento nas aulas e com os assuntos abordados.

Corroborando essa opinião, Nicola e Paniz (2016) afirmam que quando um recurso utilizado demonstra resultados positivos no processo ensino-aprendizagem, o aluno tornase mais confiante, capaz de se interessar por novas situações de aprendizagem e de construir conhecimentos mais complexos.

A única ressalva apontada pelos discentes em relação à forma como as impressões 3D foram utilizadas e as deficiências em geral do processo foi que, segundo eles, poderia se 
extrair mais proveito ainda delas, se o recurso houvesse sido utilizado com maior frequência no decorrer do semestre letivo, nas aulas assim como nas monitorias.

Um número maior e mais variado de objetos impressos também seria bem recebido pelos discentes, de tal modo que ocorreu a sugestão, inclusive, de o professor levar às aulas pórticos e estruturas completas confeccionados com a tecnologia de prototipagem rápida. Essas opiniões evidenciam mais ainda a aceitação assim como a melhoria no processo ensino-aprendizagem obtida com este trabalho.

\section{O PAPEL DAS TECNOLOGIAS NA FORMAÇÃO}

Diante do panorama de influência das tecnologias atualmente, buscamos saber a opinião da turma em relação a essa inserção tecnológica no ensino da Engenharia Civil. $\mathrm{Na}$ opinião dos alunos, o uso das tecnologias mais atuais ainda é pouco comum na universidade. Nesse sentido, eles acreditam que deveria haver maior engajamento das instituições na promoção do uso tecnológico nas metodologias de ensino atuais.

Essa é uma ideia compartilhada pelo próprio MEC (2008 apud Silva et al., 2017); para este, embora ao longo dos anos os recursos didáticos tradicionais venham sendo cada vez mais incorporados à prática pedagógica dos educadores, são necessárias mais inovações por parte dos professores a fim de complementar o aprendizado. Reforçando, Silva et al. (2017) citam que, atualmente, boa parte dos alunos têm acesso a diversos recursos tecnológicos; então, é necessário, mais do que nunca, que os docentes tomem conhecimento desses recursos para buscar complementos interessantes às aulas expositivas, muitas vezes seguidas com um único recurso que é o livro didático.

Em entrevista, o Participante 04 afirmou ser muito importante inserir as novas tecnologias, tanto para o aprendizado do aluno quanto para a sua vida profissional. Para ele, é possível assimilar muito melhor o conteúdo e de forma mais rápida, além de aprimorar sua visão dos problemas com o uso adequado desse tipo de metodologia. No que diz respeito ao âmbito profissional, ele considera também importante o uso de tais recursos, pois, estando a par das tecnologias, o indivíduo pode desenvolver produtos e técnicas novas e com o domínio da tecnologia ele também estará à frente de diversos concorrentes do mercado, em termos de atualização.

Enquanto isto, o docente do componente curricular Estruturas de Aço reconhece a importância de se inserir novas tecnologias no ensino superior, mas acredita que é preciso também valorizar os métodos e recursos tradicionais.

No caso das impressões 3D, ele considera interessante a sua utilização em aula, porque facilita $o$ entendimento da geometria. Entretanto, faz parte de suas preocupações o fato de os estudantes terem dificuldades em entender a representação bidimensional. Ele acrescenta que o profissional deve desenvolver tanto a capacidade de interpretação de uma representação $3 \mathrm{D}$ quanto $2 \mathrm{D}$, pois sem isso pode ser que no futuro os projetistas não consigam mostrar seus projetos da forma clássica, porque não se entenderá o projeto executivo se não forem entendidos os problemas $2 \mathrm{D}$ e não seria viável trabalhar sempre com projetos 3D nas obras.

\section{CONCLUSÕES}

A impressão 3D, conforme tratou-se ao longo deste trabalho, possui uma pluralidade de aplicações. Neste estudo, ela foi relacionada à didática e ao conhecimento da Engenharia de Estruturas, com a sugestão da impressão 3D como ferramenta de facilitação do processo ensino-aprendizagem do componente curricular Estruturas de Aço, em que se obteve resultados verdadeiramente positivos.

De acordo com os dados aqui expostos, verificou-se que quando utilizadas de forma planejada, nos momentos adequados e de acordo com os objetivos da aula estabelecidos pelo docente em seu plano didático, as impressões 3D constituem uma poderosa ferramenta facilitadora do aprendizado do componente curricular apontado. 
A utilização das peças confeccionadas durante o estudo possibilitou aos discentes consultados uma aproximação da realidade dos projetos de estruturas metálicas durante as aulas, que são predominantemente teóricas, auxiliando na superação de uma das causas das dúvidas relatadas - a escassez de obras com estruturas de aço na região. O próprio docente percebe tal cenário e ressalta que as dúvidas relacionadas à montagem das estruturas reduziram entre os alunos que analisaram bem as peças levadas à aula e à monitoria.

Embora algumas dificuldades tenham surgido ao longo do desenvolvimento deste trabalho, todos os seus objetivos propostos foram alcançados com sucesso e, portanto, ele contribui com a complementação dos conhecimentos multidisciplinares existentes, relacionando a educação e a Engenharia de Estruturas e, ainda, sugere uma melhoria na didática dos docentes dos cursos de Engenharia Civil.

\section{REFERÊNCIAS}

AGUIAR, L. C. D. Um processo para utilizar a tecnologia de impressão 3D na construção de instrumentos didáticos para o ensino de ciências. 2016. Dissertação (Mestrado) - Educação para a Ciência, Faculdade de Ciências, Universidade Estadual Paulista Júlio de Mesquita Filho, Bauru, 2016.

BARBOSA, P. O. D. Recursos didáticos aplicados nos cursos de qualificação profissional: um estudo de caso no CEFET-PR. 2001. Dissertação (Mestrado) - Engenharia de Produção, Universidade Federal de Santa Catarina, Florianópolis, 2001.

FELDKERCHER, N. Formação de professores, práticas pedagógicas, metodologias de ensino e de aprendizagem: estudos que incitam reflexões. Rebes: Rev. Brasileira de Ensino Superior, Passo Fundo, p.1-4, dez., 2015.
GIL, A. C. Métodos e técnicas de pesquisa social. São Paulo: Atlas, 2008.

GUARNIER, C. R. F. Metodologias de detalhamento de estruturas metálicas. 2009. Dissertação (Mestrado) Engenharia Civil, Universidade Federal de Ouro Preto, Ouro Preto, 2009.

KARLING, A. A. A didática necessária. São Paulo: IBRASA, 1991.

LIMA, P. G. Educação, ciência \& tecnologia: discussões e travessias. Laplage em Revista, Sorocaba, v. 3, n. 2, p.1-4, jun., 2017.

MACHADO, F. C.; LIMA, M. F. W. P. O uso da tecnologia educacional: um fazer pedagógico no cotidiano escolar. Scientia Cum Industria, Caxias do Sul, v. 5, n. 2, p. 44-50, set., 2017.

MARTINS， V. H. C. Impressão 3D: uma abordagem de produção mais limpa? 2017. Dissertação (Mestrado) Engenharia Industrial, Universidade de Minho, Braga, 2017.

MORAN, J. M. Novas tecnologias e mediação pedagógica. Campinas: Papirus, 2000.

NICOLA, J. A; PANIZ, C. M. A importância da utilização de diferentes recursos didáticos no ensino de biologia. Infor, Inov. Form., Rev. NEaD-Unesp, São Paulo, v. 2, n. 1, p. 350-375, 2016.

SILVA, A. C. M. et al. A importância dos recursos didáticos para o processo ensinoaprendizagem. Arquivos do Mudi, v. 21, n. 2, p. 20-31, 2017.

TULIO, M. Recursos didáticos e sua importância para as aulas de geociências no $6^{\circ}$ ano do ensino fundamental (Colégio Estadual Antonio e Marcos Cavanis/Castro-PR). Os Desafios da Escola Pública Paranaense na 
Perspectiva do Professor PDE, Paraná, n. 1, 2013. Disponível em: $<$ http://www.diaadiaeducacao.pr.gov.br/p ortals/cadernospde/pdebusca/producoes_p de/2013/2013_uepg_geo_artigo_mariliz_t ulio.pdf>.

UFERSA, Universidade Federal Rural do Semi- Árido. Projeto Pedagógico do Curso de Engenharia Civil. Pau dos Ferros-RN, 2017.
VAILLANT, D.; MARCELO, C. Ensinando a ensinar. As quatro etapas de uma aprendizagem. Curitiba: Editora da Universidades Tecnológica Federal do Paraná, 2012.

\section{DADOS BIOGRÁFICOS DOS AUTORES}
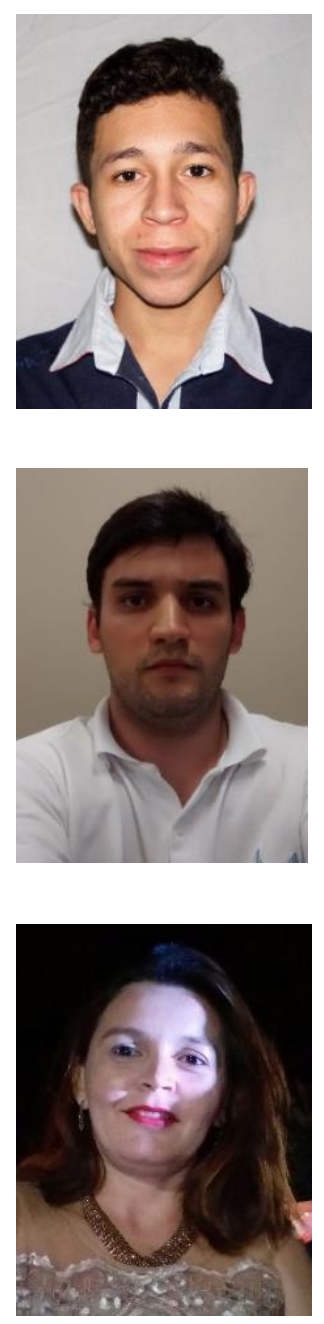

José Henrique Maciel de Queiroz - Bacharel em Ciência e Tecnologia em 2016 e em Engenharia Civil em 2018, ambos pela Universidade Federal Rural do SemiÁrido - UFERSA. Atualmente, professor na UFERSA Centro Multidisciplinar Pau dos Ferros com área de concentração em Engenharia de Estruturas e Geotecnia.

Matheus Fernandes de Araújo Silva - Graduado em Engenharia Civil pela UFRN em 2011. Mestre em Engenharia de Estruturas em 2013 pela USP - Escola de Engenharia de São Carlos. Doutorando em Engenharia de Estruturas desde 2013 pela mesma instituição. Atualmente, professor na UFERSA, Centro Multidisciplinar de Pau dos Ferros. Possui interesse no comportamento ao cisalhamento e em simulação numérica de estruturas de concreto armado.

Hortência Pessoa Rêgo Gomes - Graduada em Pedagogia pela Universidade do Estado do Rio Grande do Norte (2002). Curso de Geografia em andamento. Especialização em Educação Ambiental e Geografia do Semiárido, pelo Instituto Federal de Educação Tecnológica do Rio Grande do Norte, IFRN (2010). Mestrado Acadêmico em Ensino do Programa de Pós-Graduação em Ensino - Área de Ensino de Ciências Humanas e Sociais da UERN. Atualmente, pedagoga da Universidade Federal Rural do Semiárido. Tem experiência na área de Educação Básica e Educação Superior, com ênfase em Educação. 